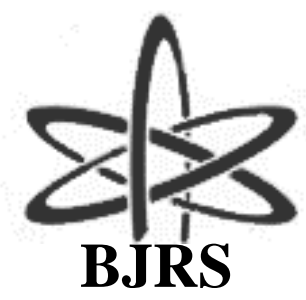

\author{
BRAZILIAN JOURNAL \\ $\mathrm{OF}$ \\ RADIATION SCIENCES \\ 07 (2019) 01-24
}

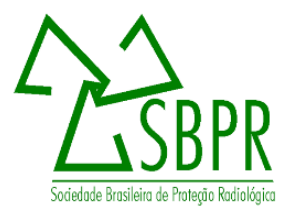

\title{
Inhibition of nitric oxide synthase activity and chemokine (CXCL12) supplementation can improve hematopoietic reconstitution in mice lethally irradiated by ${ }^{60} \mathrm{Co}$ gamma radiation
}

\author{
Vieira $^{\mathrm{a}}$, D.P., Galisteo Jr. ${ }^{\mathrm{b}}$, A.J., de Andrade Jr. ${ }^{\mathrm{b}}$, H.F. \\ ${ }^{a}$ Instituto de Pesquisas Energéticas e Nucleares, IPEN-CNEN/SP/ \\ Laboratory of Radiobiology/Center of Biotechnology, 05508-000, Sao Paulo, SP, Brazil \\ ${ }^{b}$ Instituto de Medicina Tropical de São Paulo, FMUSP, USP/ \\ Laboratório de Protozoologia, 05403-000, Sao Paulo, SP, Brazil. \\ dpvieira@ipen.br
}

\begin{abstract}
Reduction of nitric oxide (NO) production is related to increased survival in some models of infection and ionizing radiation (IR) exposure. The work used lethally irradiated $\left({ }^{60} \mathrm{Co}, 8 \mathrm{~Gy}\right) \mathrm{C} 57 \mathrm{Bl6j}$ mice, treated or not with aminoguanidine (AG), an inhibitor of an isoform of nitric oxide synthase (iNOS). Also tested iNOS ${ }^{-/-}$knockout $^{-}$ mice and a distinct group treated intraperitoneally with synthetic CXCL12, a homing chemokine related to hematopoietic reconstitution after IR exposures. Aminoguanidine treatment lead to an overshoot of proliferation of hematopoietic $\mathrm{CD}^{+}{ }^{+}$cells in bone marrows (day 2 after IR) and spleens (days 2 and 4 after IR) of irradiated mice, showing a compensative response of these organs against deleterious effects of radiation. CXCL12 mRNA production was increased on spleens of AG-treated mice at day 2 after IR, but not on other periods neither in bone marrows. CXCL12 administration did not alter $\mathrm{CD} 34^{+}$counts but seemed to keep circulating platelet counts in levels comparable to controls. Thus, CXCL12 and AG administration could help on bone marrow repopulation after critically exposed individuals.
\end{abstract}

Keywords: nitric oxide, CXCL12, hematopoiesis 


\section{INTRODUCTION}

Exposure to ionizing radiation (IR) can induce clastogenic effects in biological systems. In unicellular organisms, these effects are clearer and more evident due to its reduced complexity [1]. On the other hand, IR-exposed multicellular organisms can develop a wide range of symptoms, dosedependent or not. In humans, total or partial body exposures induce well characterized syndromes. Even in low dose/dose rates incidences, IR-exposed individuals can suffer from radiation-induced hematopoietic syndrome (RIHS), characterized by early neutropenia and thrombocytopenia and late erythrocytopenia [2]. In this way, an IR-exposed person would require urgent and sometimes expensive clinical care regarding its immunological safety and spontaneous bleeding and anaemia prevention. In some cases, bone-marrow transplantation (BMT), if available, can be prescribed and constitutes the ultimate and technically more efficient solution for hematologic recovery from IR exposures [3].

Pancytopenia is also frequent in exposed individuals, and it is related to disseminated death of hematopoietic cell precursors. Their increased radiosensitivity due its increased proliferation potential is an important inducing RIHS factor, and studies on radioprotection of bone marrow cells were carried to assess which therapy could be employed to better recover these patients [4-6]. These studies tested some important parameters, as repopulating potential of hematopoietic stem cells using CFU (colony-forming unit) assays, and cell-surface phenotyping by flow cytometry techniques to determinewhich cell populations can potentially rescue from IR-induced effects, and which can keep their proliferation and differentiation capabilities. Its expression was observed in hematopoietic precursors [7] and in endothelial cells [8]. In a simplistic manner, counts of cells bearing a $\mathrm{CD} 34^{+}$phenotype frequency in hematopoietic organs cell suspensions can be a start point to determine whether a therapy may be effective in recovering the cellularity of hematopoietic tissues Many protocols relying in CD34+ counts were described for this purpose, including clinical uses [9, 10].

To the moment, cytokine-based cocktails, mostly constituted by G-SCF (Granulocyte colonystimulation factor), and SCF (Stem cell factor) [11] showed the most promising results. Although its prominent efficacy, cytokine-based therapies have elevated costs because of the need of proteins with high levels of purity and activity. A primordial chemokine, CXCL12 (stromal cell-derived factor CXC motif chemokine ligand factor 12) was included in these cocktails after the studies re- 
ported by some authors. The death and activation processes of stem cells are controlled by a group of mesenchymal cells, with various denominations, which are sensitive to tissue destruction and, upon termination of the offending event, are able to promote activation of those stem cells and recovery of hematopoietic tissue [12]. These mesenchymal populations occur in low prevalence in tissues, usually serving as support for many effector cells. Their function relies on intercellular messaging to attract or activate target cells in environmental balance and in contact with many other cell populations [13]. One important product of these cells is CXCL12 (Stromal cell-derived factor), name of a group of CXC chemokines that are expressed into six isoforms, being $\alpha$ and $\beta$ the most important ones [14], derived from different transcripts of a single gene, SDF-1, located on chromosome 10. The action of CXCL12 is related to the presence of its specific receptor, CXCR4, which when activated can promote the proper settlement of primary mesenchymal cells [15]. The importance given to this chemokine has increased due to evidence that its action can improve homing of stem cells in bone marrow after transplantation [16]. Using another approach to study the hematopoietic recovery phenomena after irradiation, some molecules were already described as modifiers of response to radiation, which can minimize IR deleterious effects. The most common mechanism relies on the radical scavenging by vegetal flavonoids $[17,18]$, for example.

Nitric oxide is produced by mammalian cells mainly through L-arginine degradation into Lcitrulline and NO by a family of nitric oxide synthases, named NOS. These synthases are described as having three main isoforms: nNOS, neuronal, eNOS (endothelial) and iNOS, formerly named as the inducible form of NOS [19].

iNOS (Nitric oxide synthase - inducible) was described as an important factor in immune responses against infectious agents [20,21], and its importance in radiation induced damage has been studied in last years. Increased amounts of NO can be found in tissue sites damaged by IR effects, by iNOS over expression of damaged cells or by macrophages [22], and NO can react with peroxides that are also present in living cells after IR exposures, producing peroxynitrite (ONOO$\left.{ }^{-}\right)$and inducing more DNA damage than originally observed soon after exposure [23, 24].

Reduction of iNOS expression or its activity was proposed by some authors as one possible protection pathway against IR induced damage in exposed cells. Among described inhibitors, one of the most studied is aminoguanidine [25]. The release of NO by irradiated cells is related to apop- 
tosis triggering through p53 activation [26]. Its production during inflammation is performed by iNOS, after events initiated by NF- $\kappa \mathrm{B}$ activation [27], through oxidization of L-arginine and induced by inflammatory cytokines such as IL-1 $\beta$ (Interleukin 1-beta) and TNF- $\alpha$ (Tumour necrosis factor - alpha) [22] and IFN- $\gamma$ (Interferon - gamma) [28].

This work aimed to test whether orally administered aminoguanidine or iNOS genetic knockout could affect haematological parameters as platelet counts in blood samples collected from gammairradiated animals by a ${ }^{60} \mathrm{Co}$ source in a single $8 \mathrm{~Gy}$ dose and compare its effects with administration of a homing chemokine, CXCL12. This study also tested if aminoguanidine and/or CXCL12 administration can reduce tissue ablation or increase counts of progenitor $\mathrm{CD}_{3} 4^{+}$cells at hematopoietic sites. Additionally, CXCL12 mRNA expression was tested in 8Gy irradiated mice trying to relate chemokine expression levels, iNOS inhibition and hematopoietic damage after IR exposure.

\section{MATERIALS AND METHODS}

\subsection{Aminoguanidine administration}

Aminoguanidine (Sigma A-7259) was dissolved in water upon $\mathrm{H}_{2} \mathrm{SO}_{4}$ tittering in a $2 \mathrm{~g} / \mathrm{L}$ concentration. Solution had their $\mathrm{pH}$ corrected to 7.0 and were given to treated group mice as drinking water during all experiment. It was assumed that aminoguanidine hemisulphate was formed after titration and therefore administrated orally to animals as drinking water ad libitum.

\subsection{Synthetic mouse CXCL12 administration}

Liophilized synthetic mCXCL12 was a kind gift from Prof. Nobutaka Fujii (Kyoto University) and was diluted in sterile PBS. CXCL12 treated group received $1 \mu \mathrm{g} / \mathrm{kg}$ intraperitonially at days 2,4 and 8 after irradiation. 


\subsection{Mice}

Mice were raised on the colony of the Faculty of Medicine of the University of São Paulo and kept in adequate conditions according to Experimental Animal Use Committee of Tropical Medicine of the University of São Paulo and Animal Ethics Comission of IPEN. Groups of male sixweek old C57Bl/6j mice ( $n=5$ ) obtained from Medicine School Animal Facility (Sao Paulo University) and maintained at Protozoology Laboratory of Institute of Tropical Medicine of Sao Paulo. iNOS $^{-/-}$knockout mice were obtained from animal facilities of Biomedical Sciences Institute (University of Sao Paulo). All groups were gamma-irradiated inside a ${ }^{60} \mathrm{Co}$ panoramic source (Yoshizawa Kiko Co.) at the Center of Radiation Technology (IPEN/CNEN - SP) with a single 8 Gy dose, at $70 \mathrm{~cm}$ from source and behind a $70 \%$ attenuator (total attenuated dose rate: $3.372 \mathrm{kGy} / \mathrm{h}$ ). Animals were immobilized in ventilated PVC capsules $(10 \mathrm{~cm}$ length, $2 \mathrm{~cm}$ diameter) during irradiation events to prevent from heterogeneous exposure due to movement of mice during the event. Mice were sacrificed by $\mathrm{CO}_{2}$ inhalation.

\subsection{Experimental groups}

Mice were classified according with their genotypes or received treatments: nt (non-treated, irradiated group); AG (aminoguanidine-treated, irradiated group); iNOS ${ }^{-/-}$(iNOS knockout mice, irradiated group); CXCL12 (1 $\mu \mathrm{g} / \mathrm{kg}$ intraperitonially at days 2,4 and 8 after irradiation of synthetic mouse CXCL12, fed with tap water); CXCL12+AG (same as last, but have received aminoguanidine $2 \mathrm{~g} / \mathrm{L}$ in drinking water), NIC - CXCL12 (non-irradiated controls, treated with CXCL12 as above), NIC - AG (non-irradiated controls, but received aminoguanidine $2 \mathrm{~g} / \mathrm{L}$ in drinking water).

\subsection{Blood sampling}

Blood samples were collected from mice $(n=5)$ at days 0 (before irradiation), 2, 4 and 8 after irradiation. After cutting tail ends, $2 \mu \mathrm{L}$ samples of total blood were collected with pipette tips appropriately treated (immersion for 10 minutes) in sterile citrate-dextrose anticoagulant solution [0.1M $\left.\mathrm{Na}_{3} \mathrm{C}_{6} \mathrm{H}_{5} \mathrm{O}_{7}, 0.11 \mathrm{M} \mathrm{C}_{6} \mathrm{H}_{12} \mathrm{O}_{6}, 71 \mathrm{mM} \mathrm{C}_{6} \mathrm{H}_{8} \mathrm{O}_{7}\right)$ in deionized water]. Aliquots received an equal volume of turkey erythrocyte suspension (genus Meleagris) fixed in buffered formaldehyde and diluted 
in foetal bovine serum to concentration of $3 \times 10^{7}$ erythrocytes $/ \mathrm{mL}$. The concentration of mouse red cells and platelets was then determined by the ratio between counts and visualized turkey cells in 25 sight fields. Smears covered surface of glass slides and cells were stained soon after air drying using Leishman's staining.

\subsection{Histological analysis}

Mice were sacrificed at days 2, 4 and 8 after irradiation procedures. Spleen and femur fragments were aseptically removed and kept 24 hours in Sorensen's buffered formaldehyde at $4^{\circ} \mathrm{C}$ before paraffin embedding. Slices were placed on glass slides, treated and stained by hematoxylin-eosin method, visualized at 10 and $40 \mathrm{X}$ magnifications and screened for visual confirmation of tissue destruction. Only samples from nt, AG and $\mathrm{NOS}^{-/}$groups were studied by this method.

\subsection{Semi-quantitative RT-PCR to CXCL12 mRNA quantification}

Two individuals from 8Gy non-treated, aminoguanidine-treated and $\mathrm{iNOS}^{-/}$groups were tested for mRNA CXCL12 chemokine quantification using a semi-quantitative RT-PCR approach. For that, $100 \mathrm{mg}$ (spleens) or $10^{6}$ cells (bone marrows) were collected from mice irradiated at $8 \mathrm{~Gy}$, stored in TriZOL® reagent (Invitrogen) and processed following manufacturer instructions. After extraction, the RNA solutions were quantified by UV spectrophotometry, its concentration adjusted to $5 \mu \mathrm{g} / \mu \mathrm{L}$ and used as template for the construction of the corresponding cDNA libraries using Oligo-d $\mathrm{T}_{12-18}$ primers in reactions with presence of M-MuLV reverse transcriptase. Obtained cDNA libraries were used as template for amplifications of a fragment of $410 \mathrm{bp}$ belonging to the $s d f-1$ gene, which encodes murine CXCL12 gene (GenBank: NM_021704, 1837 bp) by PCR reactions using specific buffer (7.5mM Tris- $\mathrm{HCl}, \mathrm{pH}$ 9.0. $\left.0.2 \mathrm{mM} \mathrm{MgCl}_{2}, 5 \mathrm{mMKCl}^{2} 2 \mathrm{mM}\left(\mathrm{NH}_{4}\right)_{2} \mathrm{SO}_{4}\right)$, dNTP's $(2.5 \mu \mathrm{M})$ and Taq DNA polymerase $(5 \mathrm{U} / \mu \mathrm{L})$. The specific primers for amplification of CXCL12 (410bp) from cDNA templates were: CTCGGTGTCCTCTTGCTGTCCA (Fsdf-1) and GGCCCTCCTCCCCACCACT (Rsdf-1), $1.5 \mu \mathrm{M}$ each. The reactions were carried for 35 cycles with annealing temperature at $72.2^{\circ} \mathrm{C}$. As amplification controls, amplified products from murine $\beta$-actin were used. Mouse $\beta$-actin products were amplified using TGGAATCCTGTGGCATC- 
CATGAAAC (F) and TAAAACGCAGCACAGTAACAGTCCG (R) primers, also for 35 cycles and annealing temperature to $55.6^{\circ} \mathrm{C}$ (349 bp) [29]. The products of these amplifications were resolved in polyacrylamide gels $(6 \%)$ in TBE (Tris-Borate EDTA, $\mathrm{pH}=8.0$ ), stained with silver nitrate impregnation and oxidization by formaldehyde and $\mathrm{NaOH}$. Gels were photographed, and band optical densities were digitally obtained by measuring the intensity of staining of individual bands by ImageJ software (v.1.36). - The quantification of each band that represents the mRNA expression of CXCL12 was given as the relative optical density units in relationship to optical densities measurements of $\beta$-actin bands, for each sample. Only samples from nt, AG and iNOS ${ }^{-/-}$groups were studied by this method.

\subsection{Determination of $\mathrm{CD}^{+} 4^{+}$counts by flow cytometry}

Spleens and femurs were removed from two individuals from each group. Spleens were dissociated in sterile phosphate buffered saline solution (PBS pH 7.6) with foetal bovine serum (FBS, $10 \%$ ) in sterile Petri dishes until obtention of single-cell suspensions. Splenic suspensions were centrifuged through a density gradient (Ficoll-Paque ${ }^{\circledR}$, GE LifeSciences) at 1500rpm for 15 minutes at room temperature. Polimorfonuclear fractions were collected to new tubes, centrifuged as above, diluted in $100 \mu \mathrm{L}$ of PBS+FBS and kept on ice. Inner septums of femurs were flushed in $2 \mathrm{~mL}$ phosphate buffered saline solution (PBS pH 7.6) with foetal bovine serum (FBS, 10\%) and EDTA $(5 \mathrm{mM})$. Bone marrow cell suspensions were washed in same solution by centrifugation (1500 rpm, 15min, RT), diluted as above and kept on ice. Splenic and bone marrow suspensions were, centrifuged and diluted in $200 \mu \mathrm{L}$ PBS+FBS and received $1 \mu \mathrm{g} / 10^{6}$ cells of PE-conjugated anti-mouse CD34 clone MEC14.7 (SANTA CRUZ) and allowed to bind for 30min at $4^{\circ} \mathrm{C}$ away from light sources until event acquisition in a FACSCalibur unit (Becton Dickinson). Acquisitions were performed until 50000 events. Results were given in fold changes of $\mathrm{CD} 34^{+}$counts relative to nonirradiated controls. Data analyses were performed using Flowing 1.6.0 software (Turku Centre for Biotechnology, Finland). Relevant events were gated to proper FSC and SSC regions and FL2 fluorescence, using procedures described as Millan-Mullhouse protocol [30]. Samples from all described groups were evaluated by this method, except iNOS ${ }^{-/}$. 


\subsection{Statistical analysis}

All collected data was analysed using Bonferroni tests (95\% confidence intervals) to find differences between groups. All analyses were performed using GraphPad Prism 7.0 software package.

\section{RESULTS AND DISCUSSION}

Supression of iNOS expression maintained CXCL12 mRNA production constant during the experiment in hematopoietic organs: in Figure 2A it is shown CXCL12 mRNA production relative to $\beta$-actin mRNA in spleen cells of $8 \mathrm{~Gy}$ irradiated mice. AG treated mice showed higher levels of chemokine mRNA expression at day 2 after irradiation $(\mathrm{p}<0.01)$ but lowered at day $8(\mathrm{p}<0.05)$ in splenic polymorphonuclear fractions comparing to same day non-treated irradiated controls (nt).

Figure 1: CXCL12 mRNA production in spleen $(A)$ and bone marrow $(B)$ cells from $8 G y$ irradiated groups. Data represents CXCL12 \% mRNA in percentage of $\beta$-actin mRNA production of samples in all days of experiment. (*) represents difference from same day control (nt; non-treated irradiated mice): $p<0.01$. (**): $p<0.05$. Error bars represent SEM from groups
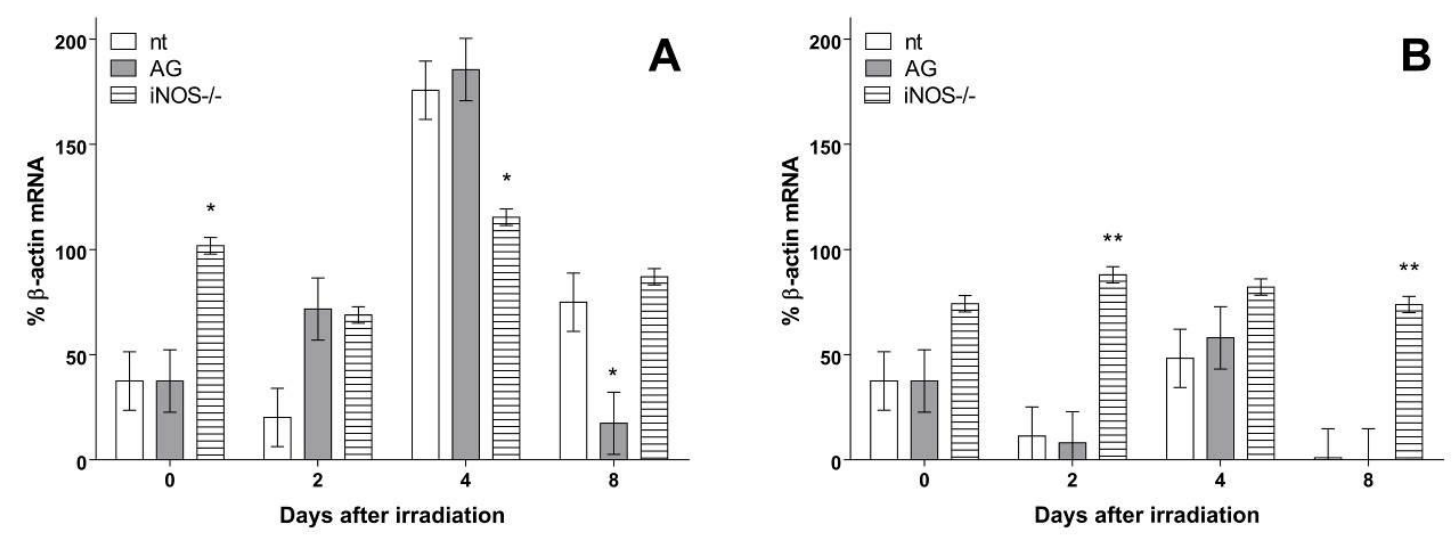

iNOS knockout mice showed higher expression levels at day 0 (before irradiation) and at day fourth after irradiation than controls. In bone marrow cells, CXCL12 mRNA production was found even more constant during the experiment, as showed in Figure 2A. iNOS knockout group showed 
higher level of chemokine expression at days 0 (before irradiation) $(\mathrm{p}<0.01)$ and eightieth after irradiation $(\mathrm{p}<0.01)$.

$\mathrm{AG}$ oral treatment increased $\mathrm{CD} 34^{+}$fractions in spleens of irradiated mice: in Figure $2 \mathrm{~A}$ it is shown fold changes in $\mathrm{CD}_{3} 4^{+}$splenic proportions from irradiated groups. It was found that treated group presents a significantly higher fold change $(\mathrm{p}<0.001)$ at day second than same day controls. Interestingly, non-irradiated aminoguanidine treated group showed even higher changes at days second $(\mathrm{p}<0.001)$ and fourth $(\mathrm{p}<0.001)$ after irradiation. Treated groups, irradiated $(A G)$ or not (NIC-AG) showed significant differences from all other groups at days 2 and 4.

Figure 2: Fold changes relative to controls of CD34+ counts in spleen (A) on bone marrow (B) cells of all groups. ${ }^{*}$ ) represents difference from same day control (nt; non-treated irradiated mice): $p<0.001 .(* *)$ Error bars represent SEM from groups.
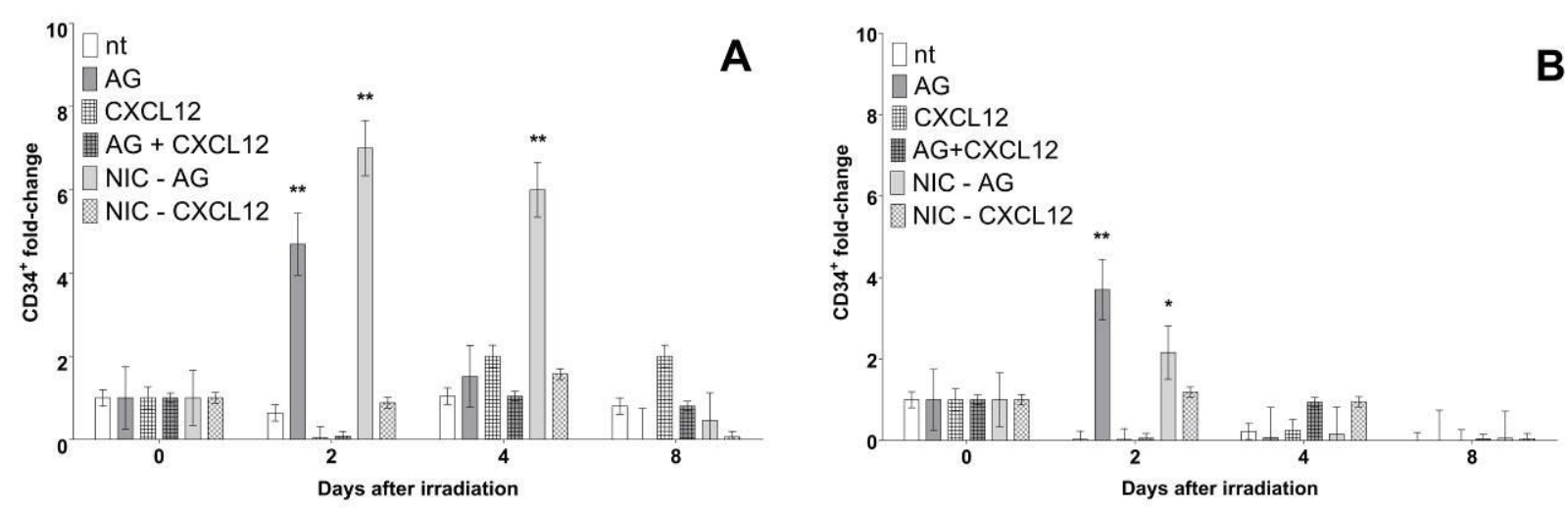

$\mathrm{CD} 34^{+}$fold changes in bone marrow counts of irradiated mice were responsible for iNOS inhibition in a similar way comparing to spleen tissue: in Figure 2B it is shown that, similarly to spleen, higher fold changes in $\mathrm{CD} 34^{+}$fraction at day 2 after irradiation occurred in bone marrow tissue $(\mathrm{p}<0.001)$. Non-irradiated treated groups also showed significantly higher levels than controls at same day $(\mathrm{p}<0.01)$. As observed in spleen cells, CD34 ${ }^{+}$fold changes of treated $(\mathrm{AG})$ and nonirradiated but treated groups (NIC-AG) were found significantly higher levels than controls at the same day $(\mathrm{p}<0.01)$.

iNOS knockout mice showed higher platelet counts comparing to all other groups: in Figure 3 it is shown platelet counts from peripheral blood of experimental groups. iNOS knockout mice 
showed significantly higher levels of platelet counts at days $0(p<0.001), 2(p<0.001)$ and 4 $(\mathrm{p}<0.05)$ of experiment comparing to controls. NOS $^{-/-}$group showed higher platelet counts comparing to all other experimental groups.

Figure 3: Platelet counts from all experimental groups during all days of experiment. . (*) represents difference from same day control (nt; non-treated irradiated mice): $p<0.001 .(* *)$ : $p<0.05$. Error bars represent SEM from groups.

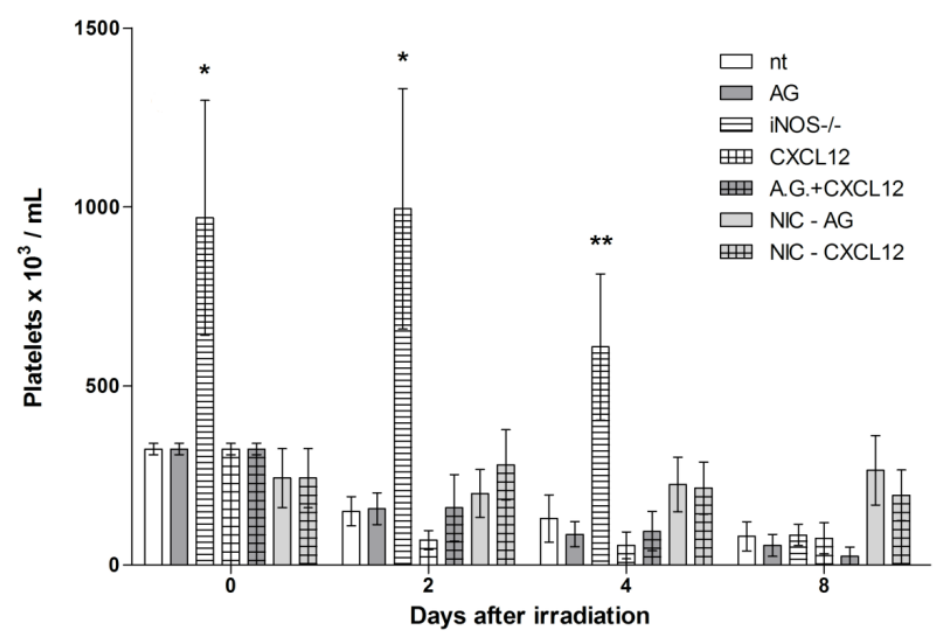

Radiation induced hematopoietic tissue ablation was decreased by iNOS suppression of expression: in Figures 4 and 5 are shown images of preparations of spleen tissue from non-treated (nt), aminoguanidine treated $(\mathrm{AG})$ and $\mathrm{iNOS}^{-/-}$mice. No relevant visual differences could be perceived between histological preparations from groups through 10 or $40 \mathrm{X}$ magnifications. Brown-colored artifacts were found to be related to hemosiderin presence.

In figures 6 and 7 are shown femoral bone marrow preparations from same groups. Preparations from iNOS-supressed groups showed less tissue destruction and more densely populated niches, more evident in preparations from knockout mice at day 8 after irradiation. In all analysed tissues, iNOS genomic knockout was more effective to prevent tissue destruction than its chemically-treated counterpart. 
Figure 4: Histological images of spleen preparations (HE stain) from non-treated, treated (aminoguanidine) and $\mathrm{iNOS}^{-/} 8$ Gy irradiated mice. Numbers on left refers to days after irradiation. Visualization: 10X. Bar: 200um. White arrows: white pulp. Red arrows: red pulp. Green arrows: hemosiderin.
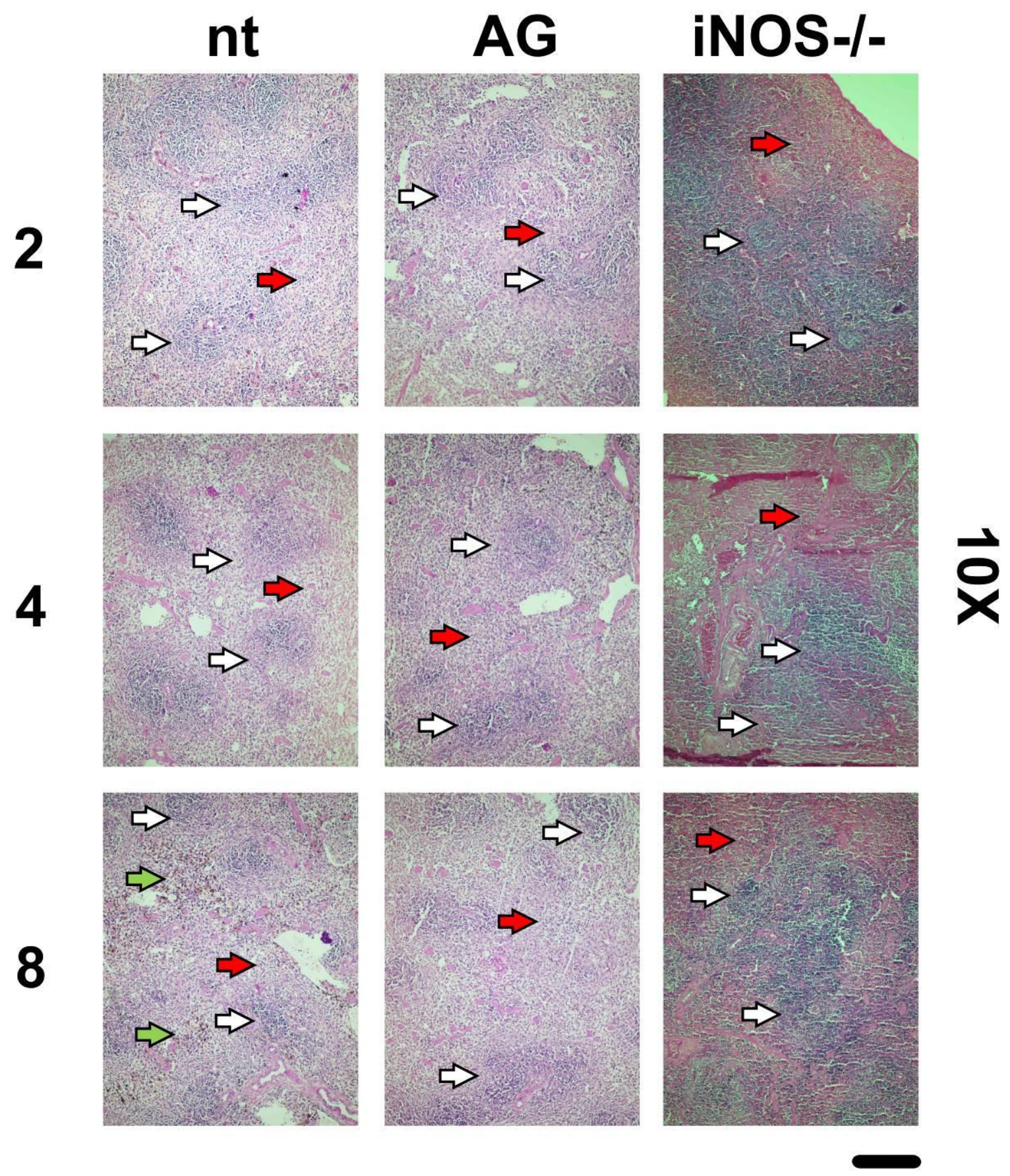
Figure 5: Histological images of spleen preparations (HE stain) from non-treated, treated (aminoguanidine) and iNOS ${ }^{-/} 8 G y$ irradiated mice. Numbers on left refers to days after irradiation.

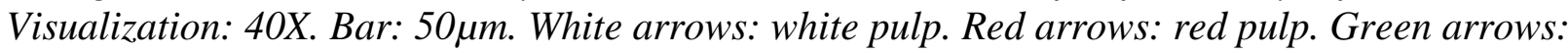
hemosiderin.
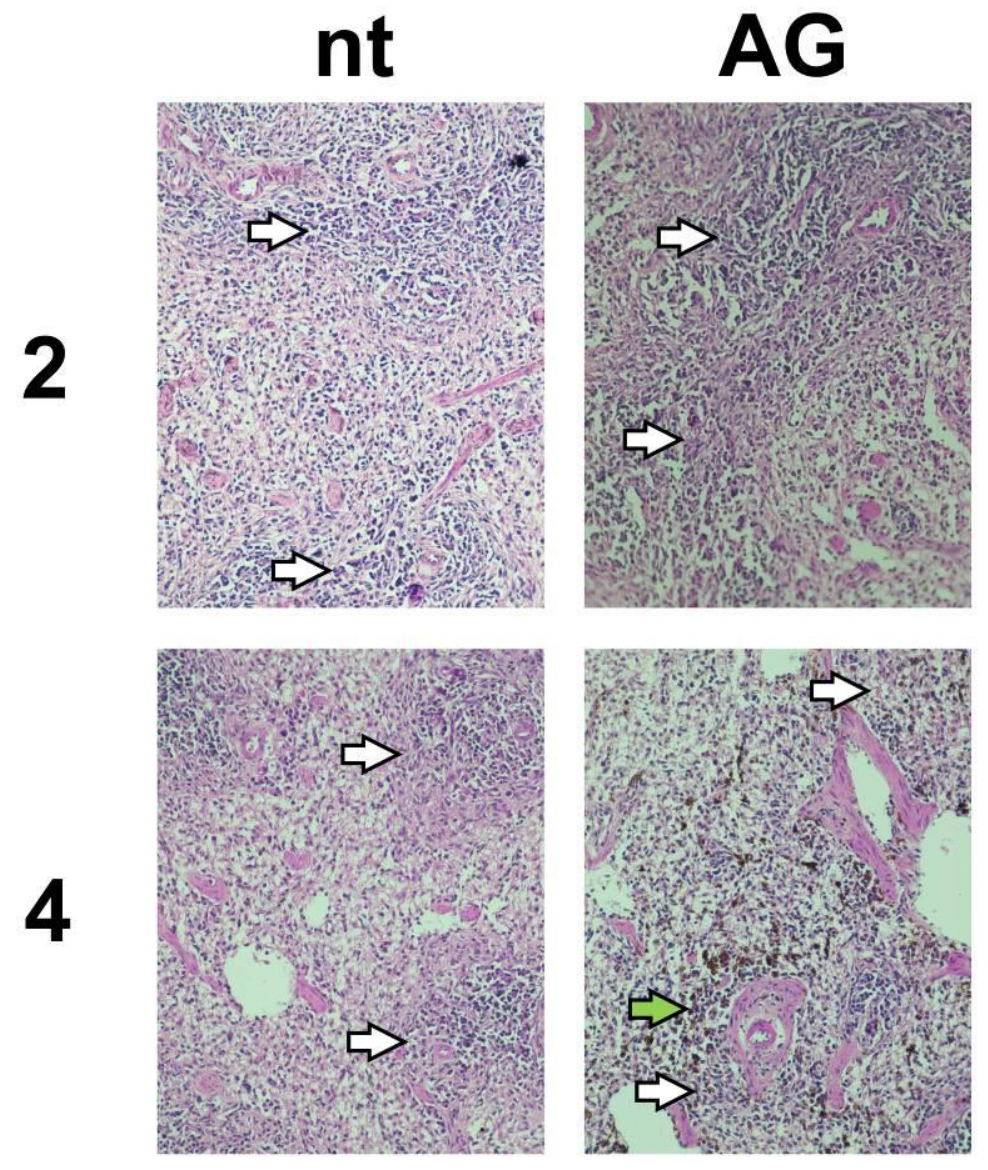

\section{iNOS-/-}
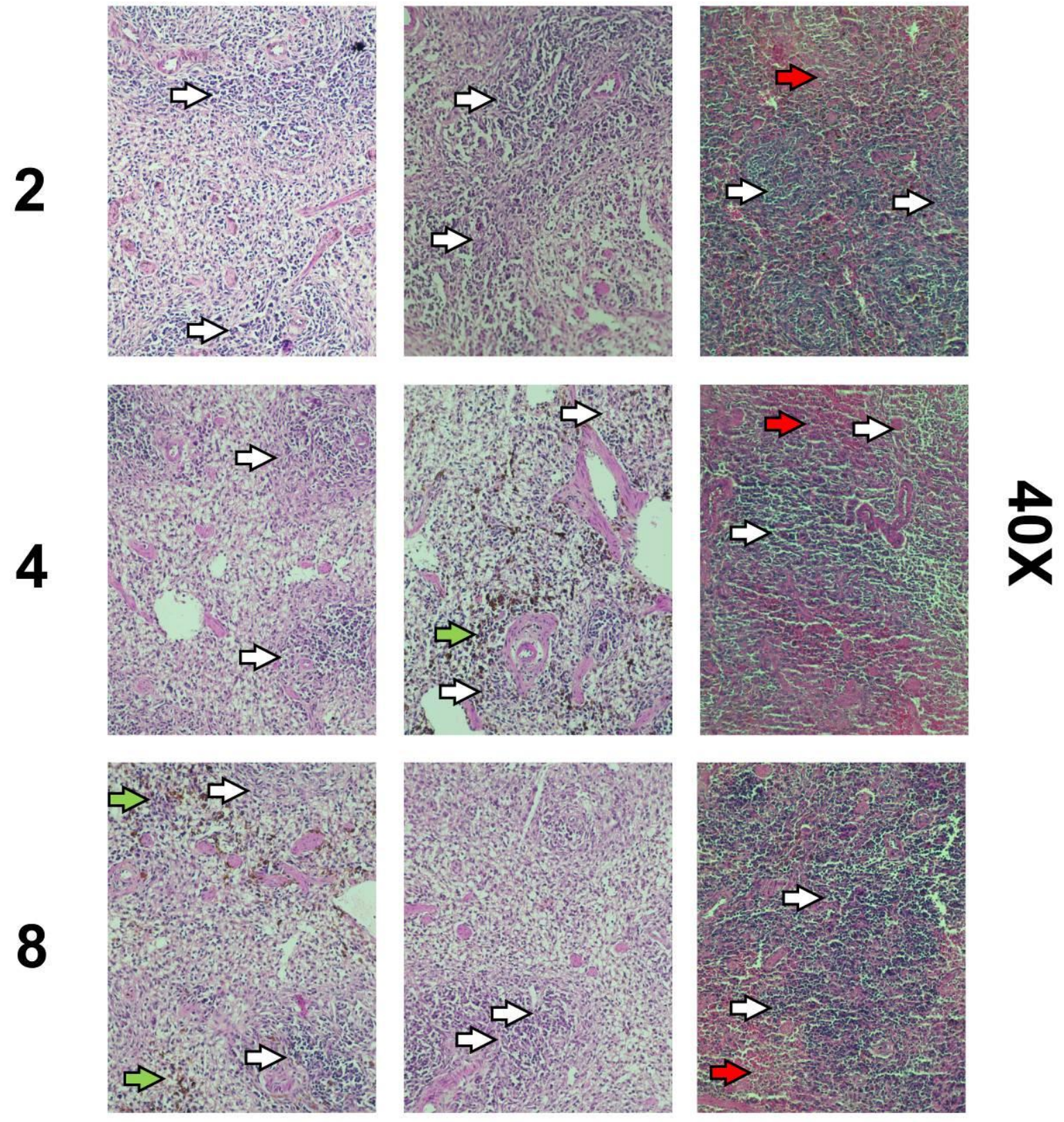
Figure 6: Histological images of bone marrow preparations (HE stain) from non-treated, treated (aminoguanidine) and $\mathrm{iNOS}^{-/-} 8 \mathrm{~Gy}$ irradiated mice. Numbers on left refers to days after ir-

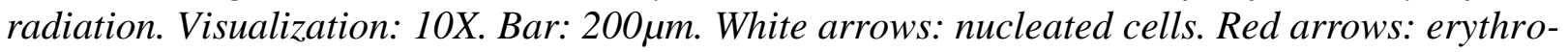
cytes. Green arrows: bone matrix.
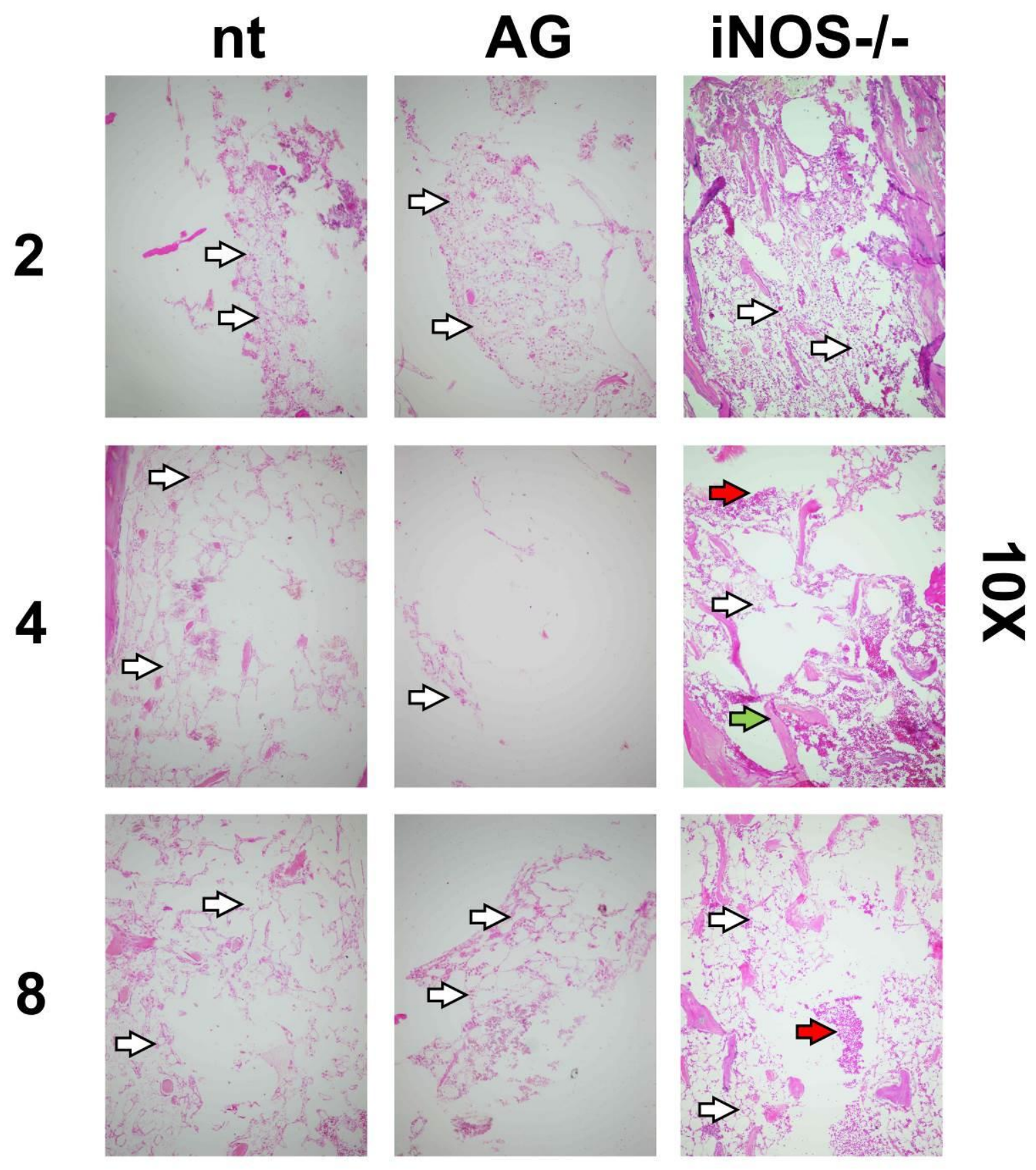
Figure 7: Histological images of bone marrow preparations (HE stain) from non-treated, treated (aminoguanidine) and $\mathrm{iNOS}^{-{ }^{-}} 8 \mathrm{~Gy}$ irradiated mice. Numbers on left refers to days after ir-

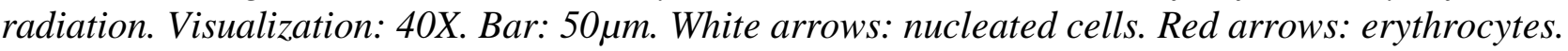
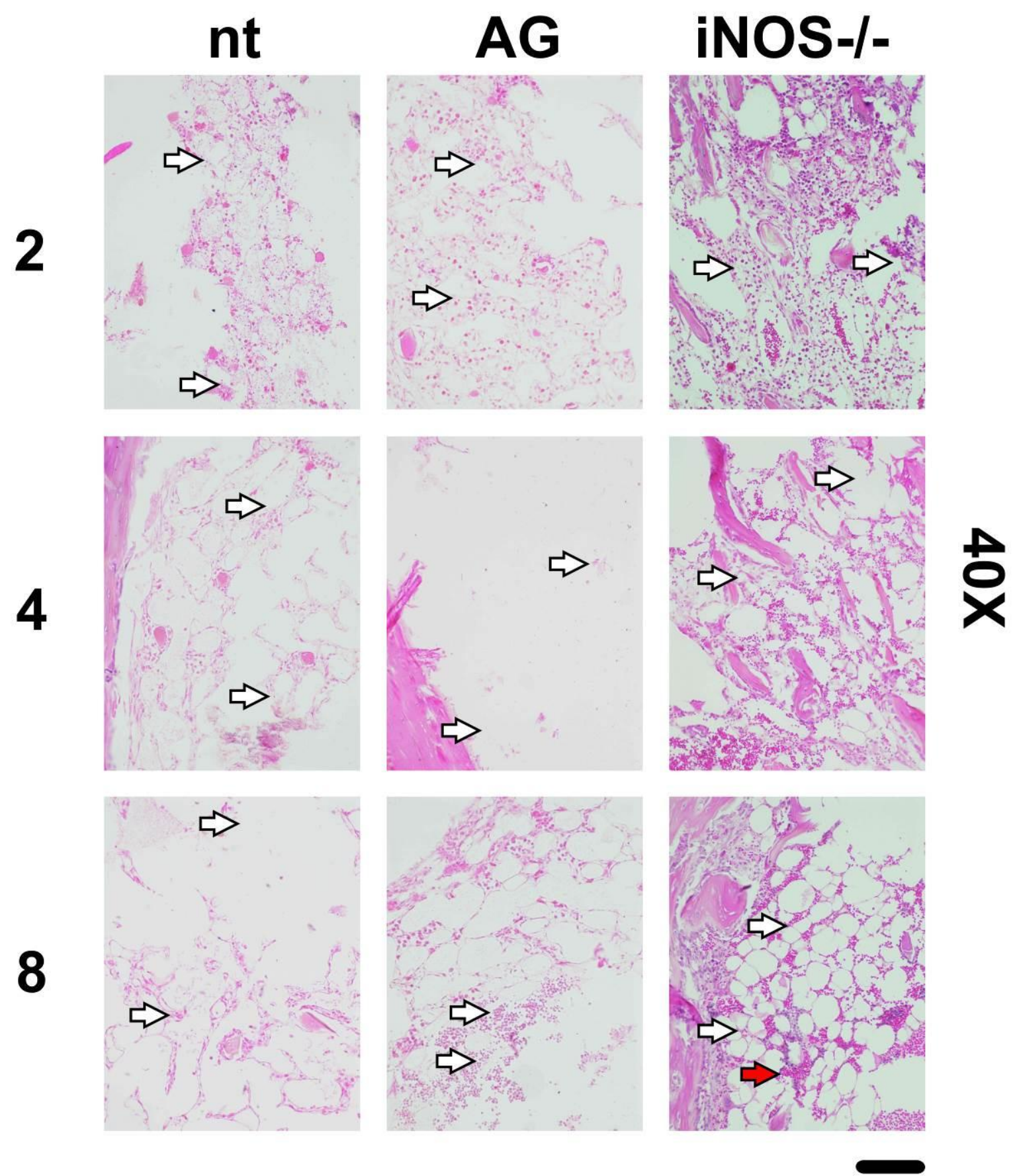
In this study AG was orally administered in mice to prevent cell death in irradiated tissues, and IR-induced hematopoietic tissue destruction, $\mathrm{CD} 34^{+}$cell recruitment to hematopoietic sites and its possible effects on platelet counts were evaluated. This work also aimed to find a relationship between iNOS inhibition and CXCL12 mRNA expression in these organs as found in models cited above.

After IR exposures, disseminated tissue destruction and increasing of necrosis and apoptosis frequencies are expected in hematopoietic tissues [31]. In rodent models, bone marrow and spleen are the major hematopoietic organs. Bone marrow tissue and cell populations are globally more radiosensitive than in splenic populations due to its greater mitotic index. In the latter case, higher counts of phagocytic cells as dendritic $\mathrm{CD} 11 \mathrm{c}^{+}$and $\mathrm{CD}_{1} 1 \mathrm{~b}^{+}[32,33]$, and larger concentration of erythrocytes due to a vast blood flow inside this organ can give this tissue more global radio resistance than bone marrow. These cells display relevant levels of differentiation and, consequently, less proliferation capability. Bone marrow cell populations are composed in majority by stem-cells with very high proliferation capacities, and thus much more susceptible to IR-exposure damaging events despite their localization inside compact bones as femurs and vertebrae.

Aminoguanidine is a selective iNOS inhibitor and its inhibition effects are much less remarkable on nNOS and eNOS isoforms [34]. Upon decreased NO production, less peroxynitrite (ONOO ${ }^{-}$ ) can be produced after reaction with intracellular peroxides, thus reducing concentration of oxidative radicals inside cellular compartments, and diminishing some deleterious effects after IR exposures. In distinct experimental models, iNOS expression could be related to increase in CXCL12 chemokine expression after NO release in splenic tissue in mice experimentally infected with a nonlethal strain of rodent malaria [29]. In the same models, CXCL12 is strongly related to immune system cell proliferation after infection [35]. In IR exposure studies, CXCL12 expression is related to bone marrow stem-cell homing [36]. In the same way, CXCL12 supplementation in irradiated experimental models can actively help recruitment of stem cells from peripheral blood and homing of these cells in hematopoietic microenvironments. In these cases, administration of CXCL12 in experimental models allows the use of fewer transplanted stem cells, or to decrease the period of "nadir" of the receiver [37].

Synthetic murine CXCL12 intraperitonially administered was found to be ineffective in altering platelet counts in the present experiments. Groups that received chemokine injections (CXCL12) 
and also $\mathrm{AG}$ in drinking water $(\mathrm{AG}+C X C L 12)$ did not develop statistically significant differences in platelet counts. The reduction of nitric oxide presence, caused by the functional blockade of its synthesis, or by gene knockout strategies, is known to reduce the adhesion and aggregation capacity of platelets [38, 39], possibly due to a signalling by cGMP-dependent protein kinase I (cGKI) [40]. If the NO absence impairs these processes, it could be possible to assume that, due to lesser extents of endothelial adhesion, circulating levels of platelets could be increased in iNOS ${ }^{-/}$mice. Also, the iNOS knockout increases vascular permeability, what could increase the number of platelets in circulating blood [41].

In spleen cells, $C X C L 12$ could not increase or even sustain $\mathrm{CD} 34^{+}$populations in irradiated tissues. Conversely, in bone marrow suspensions from irradiated CXCL12-treated groups it was found that chemokine administration reduced the proportion of these cells. Additionally, CXCL12 acts also as an antiapoptotic factor in hematopoietic stem cells, as found in other work [42], what could lead to expectation that CXCL12 administration might increase recruitment from peripheral blood and homing at bone marrow of $\mathrm{CD}^{+} 4^{+}$populations. In an inverse model, CXCL12 administration can induce MMP-2 and MMP-9 (matrix metalloproteinases 2 and 9) expression by CD34 ${ }^{+}$cells, what is enough for detachment of these cells from periosteum and subsequent escape from bone marrow environment to peripheral blood [43]. Probably the administered CXCL12 dose $(1 \mu \mathrm{g} / \mathrm{kg}$ at second, fourth and eightieth days after irradiation) was sufficiently high to trigger this kind of response.

Suppression of iNOS expression seemed to be an important factor to keep CXCL12 mRNA expression during the experiments. AG-treated mice showed significant higher levels of CXCL12 mRNA expression in spleen cells until up to four days after irradiation with $8 \mathrm{~Gy}$, but the most impacting data came from the iNOS knockout group, that kept chemokine mRNA levels constant in both organs during the experiment, but more consistent in bone marrow. The sustained CXCL12 mRNA expression could explain higher platelet counts in knockout group (8Gy irradiated), once CXCL12 expression is related to upregulation of PDGF- $\beta$ (Platelet-derived growth factor - beta), an important cytokine that attracts megakaryocytes to bone marrow stem cell niches [44].

CXCL12 mRNA presence was considered constant through duration of experiment in spleens and bone marrows of iNOS knockout mice and showed to be significantly different than controls at days 0 and 4 (spleens) and 2 and 8 (bone marrows). AG administration reduced chemokine mRNA 
levels only in spleens 8 days after irradiation. Despite numerical differences, no statistically significant differences between groups could be observed in spleens at day 2 after irradiation. In bone marrow, this chemokine is related to be expressed by vascular, perivascular and osteogenic cells [45], which are cell subtypes not classically related to be hematopoietic blood components-forming stem cells. Endothelial $\mathrm{CD} 31^{+}$cells are associated to be responsible for hematopoietic niche regeneration after radiation injury [45], leading to an interpretation in that these cell subtypes can resist to radiation damage to some extent. The presence of nitrogen-associated radicals in hematopoietic sites can reduce CXCL12 activity through nitration [46], and in inflammatory models, nitric oxide presence was shown to reduce CXCL12 gene expression [47]. In this manner, it could be possible to assume the NO absence as a putative factor of CXCL12 mRNA expression maintenance in constant levels, as showed by the work.

After exposures to $4 \mathrm{~Gy}$, the present working concentration of orally administered AG led to no visible effect on preventing tissue destruction in spleens and bone marrow from mice groups (data not shown). Treated, non-treated and iNOS knockout groups showed similar ablation levels in both organs based on visualization. In groups irradiated with $8 \mathrm{~Gy}$, it was possible to see a more evident increasing in bone marrow cellularity in treated and knockout groups, especially at the second day after irradiation, and less evident effects at day 4. AG seemed to have little protective effect while analysing the histological samples. More objective approaches could only be carried out using specific apoptosis and necrosis detection to show disseminated cell death after IR exposure.

The microscopic observation showed that, at the day 4 after irradiation, bone marrow from AGtreated group exhibits only sparse tissue strings, indicating limited tissue regeneration and/or cell proliferation. At day 8, bone marrow from nt and AG groups seemed to be in quantitively comparable states of regeneration. iNOS-deficient mice showed significant number of regeneration sites, characterized by cell strings, probably due to increased vascular permeability associated to the lack (or the reduction) of NO at hematopoietic sites [41]. The presence of erythrocytes only in bone marrow preparations of knockout mice also aid this interpretation. In addition to the sustained CXCL12 mRNA presence, indicating its constant expression, this permeability may have helped in bone marrow regeneration. Aminoguanidine administration could not induce this effect, apparently. Alternatively, histological analysis of bone marrow of AG-treated groups showed even lower cellularity than in controls, principally four days after irradiation. Another nitric oxide production inhibitor (L- 
NMMA) is found to be hematotoxic, and a relevant contributor to cellularity loss in other animal models of bone marrow depletion [48]. In this case, the authors could interpret that AG induced some toxicity, at least to a limited extent, until the day 4 of experiment. In this same day, CXCL12 mRNA presence in spleens reached its maximum value during the experiment. Considering the role of this chemokine in homing of stem cells in hematopoietic sites, and the fact that the splenic sites were showed as well-populated and in a relatively positive state of regeneration, one possible thesis could be that the hematopoietic cells from bone marrow were attracted to splenic sites. Nonirradiated and irradiated AG-treated mice showed increased $\mathrm{CD} 34^{+}$proportions in spleens, what could illustrate this phenomenon, despite not enough to keep this migratory influx and further homing after radiation-mediated depletion. Intraperitoneal injection of synthetic CXCL12 not helped in $\mathrm{CD} 4^{+}$cell homing at hematopoietic sites, even in a relatively high dose. As discussed before, the high dose probably acted as a detachment factor from hematopoietic sites [43], and the escape from bone marrow could be enhanced through the already cited increased in vascular permeation.

Regarding $\mathrm{CD}_{3} 4^{+}$counts in hematopoietic organs, AG administration induced significant increase in recruitment of this cell population in spleen and bone marrow of treated mice irradiated at $8 \mathrm{~Gy}$, more clearly at day 2 after irradiation. It was possible to find increased numbers of CD $34^{+}$ counts in the same organs at day 2 after irradiation compared to controls. Other studies worked on clarify whether iNOS/NO suppression can increase survival of high mitotic rate cell types [49]. Aminoguanidine-based iNOS inhibiting and protective effects in $\mathrm{CD} 34^{+}$pooled fractions could only be significantly observed in $8 \mathrm{~Gy}$ irradiated groups, what can be a concentration effect. Studies are discrepant when arguing whether $\mathrm{IC}_{50 \%}$ values for $\mathrm{AG}$ administration [50] are effective. Relatively to low specificity of aminoguanidine and other iNOS activity are indicative that higher concentrations must be tested. Accordingly, the present experimental design was not able to reveal differences between treated and non-treated groups in CXCL12 mRNA expression sampled in spleen and bone marrow tissues of irradiated mice. However, AG orally administered could increase CD34 ${ }^{+}$ counts in spleens from $8 \mathrm{~Gy}$ irradiated at days 2 and 4 after irradiation, and in bone marrow at day 2, suggesting that the employed concentration could induce significant changes comparing to same day control.

The work did not search for $\mathrm{CD} 4^{+}$cell populations in $\mathrm{iNOS}^{-/-}$mice, but other studies of tumoral models using same knockout mice showed increase of frequencies of endothelial CD $34^{+}$in 
osteosarcoma [51] in squamous cell carcinoma [52] and in hepatocellular carcinoma [53]. Also, $\mathrm{CD} 4^{+}$monocytes from iNOS ${ }^{-/}$mice retain enhanced viability potential [54]. Thus, the scientific evidence of $\mathrm{CD}_{3} 4^{+}$survival in iNOS depleted mice can be taken as positive and was assumed as true by this work.

\section{CONCLUSION}

iNOS genetically knocked-out mice are less susceptible to IR-induced tissue damage, and kept CXCL12 mRNA expression levels constant up to eight days after irradiation. To reproduce this effect, oral administration of aminoguanidine was provided to irradiated mice, resulting in nonevident histological modifications (by simple HE-staining). On the other hand, a significant increase in progenitor $\mathrm{CD}_{3} 4^{+}$counts were seen to occur in treated groups, despite no hematological modification could be observed among the experimental groups. The results suggest that iNOS suppression was found to be related to cellular repopulation of hematopoietic sites in mice irradiated by lethal doses.

\section{ACKNOWLEDGMENT}

The authors would like to thank Eng. Carlos Gaia and Eng. Elizabeth Somessari for technical help in irradiation procedures. Vieira, D.P. was a CNPq fellow (141113/2002-2). The work was supported by $\mathrm{CNPq}$ (Conselho Nacional de Desenvolvimento Científico e Tecnológico) (470873/2004-3) and LIMHCFMUSP.

\section{REFERENCES}

[1] VEREMEYEVA, G. et al., Long-Term Cellular Effects in Humans Chronically Exposed To Ionizing Radiation, Health Phys. 99 (3) p. 337-346, 2010.

[2] SINGH, V.K., SEED, T.M., A review of radiation countermeasures focusing on injuryspecific medicinals and regulatory approval status: part I. Radiation sub-syndromes, animal 
models and FDA-approved countermeasures, Int. J. Radiat. Biol. 93 (9) p. 851-869 , 2017.

[3] ASANO, S., Current status of hematopoietic stem cell transplantation for acute radiation syndromes, Int. J. Hematol. 95 (3) p. 227-231 , 2012.

[4] MOJENA, M. et al., Protection against gamma-radiation injury by protein tyrosine phosphatase 1B, Redox Biol. 17 (April) p. 213-223 , 2018.

[5] XIE, J. et al., Graphdiyne Nanoparticles with High Free Radical Scavenging Activity for Radiation Protection, ACS Appl. Mater. Interfaces p. acsami.8b00949 , 2018.

[6] YAMAMOTO, T., KINOSHITA, M., "Radioprotective Effect of Vitamin C as an Antioxidant", Vitamin C, InTech 450.

[7] MAMBET, C. et al., Murine models based on acute myeloid leukemia-initiating stem cells xenografting., World J. Stem Cells 10 (6) p. 57-65 , 2018.

[8] SHI, Q., SCHATTEN, G., HODARA, V., SIMERLY, C., VANDEBERG, J.L., Endothelial reconstitution by CD34+ progenitors derived from baboon embryonic stem cells, J. Cell. Mol. Med. 17 (2) p. 242-251 , 2013.

[9] PANCH, S.R., SZYMANSKI, J., SAVANI, B.N., STRONCEK, D.F., Sources of Hematopoietic Stem and Progenitor Cells and Methods to Optimize Yields for Clinical Cell Therapy, Biol. Blood Marrow Transplant. 23 (8) p. 1241-1249 , 2017.

[10] OOSTVOGELS, R. et al., In search of the optimal platform for Post-Allogeneic SCT immunotherapy in relapsed multiple myeloma: A systematic review, Bone Marrow Transplant. 52 (9) p. 1233-1240 , 2017.

[11] TAY, J., LEVESQUE, J.P., WINKLER, I.G., Cellular players of hematopoietic stem cell mobilization in the bone marrow niche, Int. J. Hematol. 105 (2) p. 129-140 , 2017.

[12] KOLLET, O. et al., Rapid and efficient homing of human CD34+ CD38-/low CXCR4+ stem and progenitor cells to the bone marrow and spleen of NOD / SCID and NOD / SCID / B2m null mice, Blood 97 (10) p. 3283-3291 , 2001.

[13] WU, J. et al., The Differentiation Balance of Bone Marrow Mesenchymal Stem Cells Is Crucial to Hematopoiesis., Stem Cells Int. 2018 p. 1540148 , 2018.

[14] YU, L. et al., Identification and expression of novel isoforms of human stromal cell-derived factor 1, Gene 374 (1-2) p. 174-179, 2006.

[15] RATAJCZAK, M.Z., ADAMIAK, M., PLONKA, M., ABDEL-LATIF, A., RATAJCZAK, 
J., Mobilization of hematopoietic stem cells as a result of innate immunity-mediated sterile inflammation in the bone marrow microenvironment - The involvement of extracellular nucleotides and purinergic signaling, Leukemia 32 (5) p. 1116-1123 , 2018.

[16] RATAJCZAK, M.Z., SERWIN, K., SCHNEIDER, G., Innate immunity derived factors as external modulators of the CXCL12 - CXCR4 axis and their role in stem cell homing and mobilization, Theranostics 3 (1) p. 3-10, 2013.

[17] SANTOS, G.S., TSUTSUMI, S., VIEIRA, D.P., BARTOLINI, P., OKAZAKI, K., Effect of Brazilian propolis (AF-08) on genotoxicity, cytotoxicity and clonogenic death of Chinese hamster ovary (CHO-K1) cells irradiated with 60Co gamma-radiation, Mutat. Res. - Genet. Toxicol. Environ. Mutagen. 762 p. 17-23, 2014.

[18] MAGALHÃES, V.D. et al., In v itro tests of resveratrol radiomodifying effect on rhabdomyosarcoma cells by comet assay, Toxicol. Vitr. 28 (8) , 2014.

[19] VANNINI, F., KASHFI, K., NATH, N., The dual role of iNOS in cancer, Redox Biol. 6 p. 334-343, 2015.

[20] DAS, P., LAHIRI, A., LAHIRI, A., CHAKRAVORTTY, D., Modulation of the arginase pathway in the context of microbial pathogenesis: A metabolic enzyme moonlighting as an immune modulator, PLoS Pathog. 6 (6), 2010.

[21] NAHREVANIAN, H., Involvement of nitric oxide and its up/down stream molecules in the immunity against parasitic infections., Braz. J. Infect. Dis. 13 (6) p. 440-8 , 2009.

[22] IBUKI, Y., GOTO, R., Ionizing radiation-induced macrophage activation: augmentation of nitric oxide production and its significance., Cell. Mol. Biol. (Noisy-le-grand). 50 Online p. OL617-26, 2004.

[23] LOWENSTEIN, C.J., PADALKO, E., iNOS (NOS2) at a glance, J. Cell Sci. 117 (14) p. 2865-2867, 2004.

[24] HANAUE, N. et al., Peroxynitrite formation in radiation-induced salivary gland dysfunction in mice., Biomed. Res. 28 (3) p. 147-51 , 2007.

[25] YANG, Y. et al., Nitric oxide synthase inhibitors: a review of patents from 2011 to the present, Expert Opin. Ther. Pat. p. 1-20, 2014.

[26] CHOI, B., PAE, H., JANG, S. Il, KIM, Y., CHUNG, H., Nitric oxide as a pro-apoptotic as well as anti-apoptotic modulator., J. Biochem. Mol. Biol. 35 (1) p. 116-26 , 2002. 
[27] ZHANG, S.-Y. et al., NF-kappaB decoy potentiates the effects of radiation on vascular smooth muscle cells by enhancing apoptosis., Exp. Mol. Med. 37 (1) p. 18-26 , 2005.

[28] HE, W., FROST, M.C., CellNO trap: Novel device for quantitative, real-time, direct measurement of nitric oxide from cultured RAW 267.4 macrophages, Redox Biol. 8 p. 383$397,2016$.

[29] GARNICA, M.R., SILVA, J.S., DE ANDRADE JUNIOR, H.F., Stromal cell-derived factor1 production by spleen cells is affected by nitric oxide in protective immunity against bloodstage Plasmodium chabaudi CR in C57BL/6j mice, Immunol. Lett. 89 (2-3) p. 133-142, 2003.

[30] GRATAMA, J., ORFAO, A., BARNETT, D., BRANDO, B., Flow cytometric enumeration of CD34+ hematopoietic stem and progenitor cells, Cytometry 34 (December 1997) p. 128$142,1998$.

[31] SHAO, L., LUO, Y., ZHOU, D., Hematopoietic Stem Cell Injury Induced by Ionizing Radiation, Antioxid. Redox Signal. 20 (9) p. 1447-1462, 2014.

[32] NIKOLIC, T., DINGJAN, G.M., LEENEN, P.J.M., HENDRIKS, R.W., A subfraction of $\mathrm{B} 220(+)$ cells in murine bone marrow and spleen does not belong to the B cell lineage but has dendritic cell characteristics., Eur. J. Immunol. 32 (3) p. 686-92 , 2002.

[33] NEMZEK, J.A., BOLGOS, G.L., WILLIAMS, B.A., REMICK, D.G., Differences in normal values for murine white blood cell counts and other hematological parameters based on sampling site, Inflamm. Res. 50 p. 523-527, 2001.

[34] ASTOLFI, R.S., KHOURI, D.G., BRANDIZZI, L.I.V., ÁVILA-CAMPOS, M.J., ANDRADE JR., H.F. de, Antagonic effect of the inhibition of inducible nitric oxide on the mortality of mice acutely infected with Escherichia coli and Bacteroides fragilis, Brazilian J. Med. Biol. Res. 40 (3) p. 317-322, 2007.

[35] GARNICA, M.R., SOUTO, J.T., SILVA, J.S., DE ANDRADE, H.F., Stromal cell derived factor 1 synthesis by spleen cells in rodent malaria, and the effects of in vivo supplementation of SDF-1alpha and CXCR4 receptor blocker., Immunol. Lett. 83 (1) p. 47$53,2002$.

[36] BASTIANUTTO, C. et al., Local radiotherapy induces homing of hematopoietic stem cells to the irradiated bone marrow, Cancer Res. 67 (21) p. 10112-10116, 2007. 
[37] HÉRODIN, F., BOURIN, P., MAYOL, J.F., LATAILLADE, J.J., DROUET, M., Short-term injection of antiapoptotic cytokine combinations soon after lethal $\gamma$-irradiation promotes survival, Blood 101 (7) p. 2609-2616, 2003.

[38] GKALIAGKOUSI, E. et al., Decreased platelet nitric oxide contributes to increased circulating monocyte-platelet aggregates in hypertension, Eur. Heart J. 30 (24) p. 3048$3054,2009$.

[39] GAWROŃSKA, B., MATOWICKA-KARNA, J., KRALISZ, M., KEMONA, H., Markers of inflammation and influence of nitric oxide on platelet activation in the course of \&lt;i\&gt;ulcerative colitis\&lt;/i\&gt;, Oncotarget 8 (40) p. 68108-68114, 2017.

[40] ANTL, M. et al., IRAG mediates NO/cGMP-dependent inhibition of platelet aggregation and thrombus formation, Blood 109 (2) p. 552-559, 2007.

[41] PASSARO, D. et al., Increased Vascular Permeability in the Bone Marrow Microenvironment Contributes to Disease Progression and Drug Response in Acute Myeloid Leukemia, Cancer Cell 32 (3) p. 324-341.e6, 2017.

[42] LATAILLADE, J.-J., Stromal cell-derived factor 1 regulates primitive hematopoiesis by suppressing apoptosis and by promoting G0/G1 transition in CD34+ cells: evidence for an autocrine/paracrine mechanism, Blood 99 (4) p. 1117-1129, 2002.

[43] LAPIDOT, T., DAR, A., KOLLET, O., How do stem cells nd their way home?, Blood 106 (6) p. 1901-1910, 2005.

[44] DOMINICI, M. et al., Restoration and reversible expansion of the osteoblastic hematopoietic stem cell niche after marrow radioablation Restoration and reversible expansion of the osteoblastic hematopoietic stem cell niche after marrow radioablation, 114 (11) p. 2333$2343,2011$.

[45] PITT, L.A. et al., CXCL12-Producing Vascular Endothelial Niches Control Acute T Cell Leukemia Maintenance, Cancer Cell 27 (6) p. 755-768 , 2015.

[46] JANSSENS, R. et al., Natural nitration of CXCL12 reduces its signaling capacity and chemotactic activity \&lt;i\&gt;in vitro\&lt;/i\&gt; and abrogates intra-articular lymphocyte recruitment \&lt;i\&gt;in vivo\&lt;/i\&gt;, Oncotarget 7 (38) p. 62439-62459 , 2016.

[47] PETKOVIĆ, F., BLAŽEVSKI, J., MOMČILOVIĆ, M., MOSTARICA STOJKOVIC, M., MILJKOVIĆ, D., Nitric oxide inhibits CXCL12 expression in neuroinflammation, 
Immunol. Cell Biol. 91 (6) p. 427-434, 2013.

[48] PUNJABI, C.J., LASKIN, J.D., HWANG, S.M., MACEACHERN, L., LASKIN, D.L., Enhanced production of nitric oxide by bone marrow cells and increased sensitivity to macrophage colony-stimulating factor (CSF) and granulocyte-macrophage CSF after benzene treatment of mice, Blood 83 (11) p. 3255-3263 , 1994.

[49] HILDEBRANDT, G. et al., Mechanisms of the anti-inflammatory activity of low-dose radiation therapy., Int. J. Radiat. Biol. 74 (3) p. 367-78, 1998.

[50] SOUTHAN, G.J., SZABÓ, C., Selective pharmacological inhibition of distinct nitric oxide synthase isoforms, Biochem. Pharmacol. 51 (4) p. 383-394 , 1996.

[51] CHEN, W.L., FENG, H.J., LI, J.S., LI, H.G., Expression and pathological relevance of inducible nitric oxide synthase in osteosarcoma of the jaws, Int. J. Oral Maxillofac. Surg. 36 (6) p. 541-544, 2007.

[52] KUMAGAI, Y. et al., Coexpression of COX-2 and iNOS in angiogenesis of superficial esophageal squamous cell carcinoma, Int. Surg. 100 (4) p. 733-743 , 2015.

[53] SUN, M.H. et al., Expressions of inducible nitric oxide synthase and matrix metalloproteinase-9 and their effects on angiogenesis and progression of hepatocellular carcinoma, World J. Gastroenterol. 11 (38) p. 5931-5937 , 2005.

[54] D’AVENI, M. et al., G-CSF mobilizes CD34+ regulatory monocytes that inhibit graft-versushost disease, Sci. Transl. Med. 7 (281) , 2015. 